\title{
Toxicokinetics of mercury in blood compartments and hair of fish-fed sled dogs
}

\author{
Camilla L Lieske*, Sara K Moses, Judith M Castellini, Jessica Klejka, Karsten Hueffer and Todd M O'Hara
}

\begin{abstract}
Background: Understanding mercury $(\mathrm{Hg})$ distribution in blood and the importance of hair as an excretory pathway is critical for evaluating risk from long term dietary $\mathrm{Hg}$ exposure. The major objective of this study was to characterize changes in total $\mathrm{Hg}$ concentrations in specific blood compartments and hair over time due to long term piscivory.

Methods: Eight sled dogs (Canis lupus familiaris) were fed either a fish and kibble diet $(n=4)$, or a fish-free control diet $(n=4)$ for 12 weeks. Concentrations of $\mathrm{Hg}$ were monitored throughout the exposure period, and for 10 weeks post exposure, until Hg concentrations in all blood compartments of one of the exposed dogs dropped below detection limit. Additionally, foreleg hair was sampled during acclimation and weeks 0 and 12.

Results: Hg was detected primarily in whole blood and packed cells, although it was sporadically detected at low concentrations in plasma and serum in two of the fish fed dogs. Dogs ingested an estimated average of $13.4 \pm$ $0.58 \mu \mathrm{g} \mathrm{Hg}$ per kg body weight per day. Hg was detectable in whole blood and packed cells within a week of exposure. Detected concentrations continued to rise until plateauing at approximately 3-6 weeks of exposure at a mean of $9.2 \pm 1.97 \mathrm{ng} / \mathrm{g}(\mathrm{ppb})$ in whole blood. Hg concentration decreased post exposure following $1 \mathrm{st}$ order elimination. The mean half-life $\left(\mathrm{t}_{1 / 2}\right)$ in whole blood for $\mathrm{Hg}$ was 7 weeks. Mean $\mathrm{Hg}$ in hair for the fish-fed dogs at week 12 was $540 \pm 111 \mathrm{ppb}$ and was significantly greater (about 7-fold) than the Hg hair concentration for the control dogs. The hair to blood ratio for $\mathrm{Hg}$ in fish-fed dogs was $59.0 \pm$ 7.6:1.

Conclusions: This study found the sled dog model to be an effective method for investigating and characterizing blood Hg distribution (whole blood, serum, plasma, packed cells) and toxicokinetics associated with a piscivorous diet, especially for $\mathrm{Hg}$-exposed fur bearing mammals (such as polar bears). Although hair excretion and hair to blood $\mathrm{Hg}$ ratios were not similar to human concentrations and ratios, the sled dog toxicokinetics of $\mathrm{Hg}$ in blood, was more similar to that of humans than traditional laboratory animals (such as the rat).
\end{abstract}

Keywords: mercury, piscivore, canine, toxicokinetics, hair-excretion, hair to blood ratio

\section{Background}

Conflicting studies have been published either extolling the benefits of a fish diet or cautioning against the risks of mercury $(\mathrm{Hg})$ and other contaminants exposure [1-6]. Because of the importance of a marine based diet in many populations, both human and wildlife, it is critical to understand how $\mathrm{Hg}$ is absorbed, distributed, and eliminated in association with piscivory.

Many communities within Alaska rely on fish and other biota for subsistence. Sled dogs frequently live in

\footnotetext{
* Correspondence: cllieske@alaska.edu

University of Alaska Fairbanks, Institute of Arctic Biology, 902 N Koyukuk Dr, Fairbanks, AK, 99775-7000, USA
}

close proximity to humans and consume the same diet. Published fish consumption advice for Alaskans developed by the Alaska Scientific Advisory Committee for Fish Consumption recommend an acceptable daily intake level (ADIL) of $\mathrm{Hg}$, based on consumer body weight (BW), of $0.4 \mu \mathrm{g} / \mathrm{kg} \mathrm{BW} /$ day [7]. This is intermediate to the Health Canada fish consumption recommendations of $0.2 \mu \mathrm{g} / \mathrm{kg} \mathrm{BW} /$ day for children and women of childbearing age, and $0.5 \mu \mathrm{g} / \mathrm{kg} \mathrm{BW} /$ day for everyone else [8]. In Alaska, recommended consumption allowances have been developed for the commonly eaten fish species for the state. The amount recommended depends on the amount of $\mathrm{Hg}$ generally detected in that species (or size)

\section{() Biomed Central}


of fish. The limit for Alaskan salmon species is listed as unlimited.

Sled dogs have potential as biomonitors and models of species with a piscivorous diet. Sled dogs have been used as a surrogate to study organohalogen contaminants in top arctic predators (e.g. polar bears and arctic foxes) in Greenland [9-12], and have been found to be effective in providing direct evidence for cause and effect relationships with exposure. Hair from Alaskan sled dogs has been proposed for monitoring of $\mathrm{Hg}$ exposure [13] due to the similarity of their diet to a rural Alaskan subsistence diet. We propose utilizing sled dogs as a model of chronic exposure to $\mathrm{Hg}$ through piscivory. This model can be used to better understand toxicokinetics, toxicodynamics, relationships with chemical feeding ecology measures, genomics, etc.

Several studies have described the tissue distribution (concentrations and/or burdens) of $\mathrm{Hg}$ at a single time point $[14,15]$ and others have described the toxicology of a large $\mathrm{Hg}$ exposure $[16,17]$. Studies describing the kinetics of $\mathrm{Hg}$ in blood have been done in laboratory rodents [18-20], fish [21], birds [22], and primates [23]. The rat model, in conjunction with data from monitoring $\mathrm{Hg}$ levels in human urine, feces, hair and blood over time have been used to develop a theoretical toxicokinetic model for predicting $\mathrm{Hg}$ distribution and elimination [24], however there are significant differences in the kinetics of $\mathrm{Hg}$ between rats and humans. Additionally, many of the laboratory kinetic studies (rodent, primate and avian) focus on exposure (intravenous or oral) of methylmercuric chloride rather than exposure to $\mathrm{Hg}$ from fish consumption.

Currently there is little information on the kinetics of $\mathrm{Hg}$ in piscivores, especially at relatively low concentration exposures. In order to better understand how blood $\mathrm{Hg}$ relates to marine fish intake, captive canids (sled dogs) on a known marine diet were sampled over time. Hair was sampled at different time points to evaluate its use in biomonitoring. We propose sled dogs as a model for understanding the blood compartmentalization of a low, chronic exposure to $\mathrm{Hg}$. This paper describes the toxicokinetics of $\mathrm{Hg}$ in blood, including partitioning in whole blood (WB), serum, plasma and packed cells from serum and plasma preparations (PCserum and PCplasma).

\section{Methods \\ Animals}

The study animals were eight (four female and four male) mixed breed sled dogs (Canis lupus familiaris). Ages ranged from 3 to 8 years. Dogs were randomly assigned feeding regiments (fish-fed or kibble only) and kept in outside pens separated according to feeding groups. The dogs had access to water ad lib during the study period. Animal handling and the feeding regime were performed according to protocols approved by the University of Alaska Fairbanks Institutional Animal Care and Use Committee (protocol \#145639-2). Whole blood sampled two weeks prior to the start of the fish exposure and at week 12 of the study (the end of the fish exposure) was submitted to Veterinary Services at the University of Alaska Fairbanks for determination of clinical chemistry, hematology and evaluation of health. All dogs were found to be within expected ranges for the health parameters.

\section{Diet}

The control group ( $\mathrm{n}=4,2$ males and 2 females) was fed commercial dog kibble (Standard Choice 26\% Value Meal Dog Food, Fromm Family Foods, Mequon, WI) twice daily throughout the entire study. The fish-fed group ( $\mathrm{n}=4,2$ males referred to as dogs $\mathrm{K}$ and $\mathrm{T}$; and 2 females referred to as dogs $C$ and $M$ ) received a $50 \%$ kibble, 50\% fish diet (the same kibble as the control group for one meal and keta (chum) salmon (Oncorhynchus keta) for the other meal) to result in similar energy (caloric) intake as for the controls. The salmon was provided frozen (Interior Alaska Fish Processors, Fairbanks, AK) and cut frozen into pieces of approximately $300 \mathrm{~g}$ (range:198-458 g) prior to the start of the study. Sections ( 5 from the cranial end, 5 from the caudal end) from 10 different fish were analyzed at the beginning of the study for $\mathrm{Hg}$ to determine the range of $\mathrm{Hg}$ concentrations in the salmon fed to the dogs. These concentrations along with mass of the fish fed were used to estimate daily intake of Hg. Fish meals were packaged individually and heated in a microwave until any liquid in the package was brought to a boil to inactivate potential parasites and any thiaminase present. Packaged fish meals remained frozen $\left(-20^{\circ} \mathrm{C}\right)$ until feeding. Dogs were fed individually to control the amount of food intake per dog and the fish amount recorded for each daily feeding. The amount fed was adjusted as needed to maintain body condition and BW as determined by the primary feeder from 3 May 26 October 2010. BW was measured at each sampling event.

\section{Study Design}

The study was carried out in three phases: acclimation to kibble diet, exposure to fish meals and fish-free (kibbleonly) meals, and elimination of $\mathrm{Hg}$ phase. These phases consisted of the following: During a three-week period (3-23 May 2010), all eight dogs were on the control (fish meal-free kibble) diet. After this acclimation phase, 4 dogs (fish-fed group) were switched to a $50 \%$ marine fish, $50 \%$ kibble (one fish meal and one kibble meal per day) diet based on mass of the dog and calories required for 12 weeks (24 May-15 Aug 2010). All dogs were fed the 
commercial kibble diet (no fish) during the 10 week $\mathrm{Hg}$ elimination phase (16 August-26 October 2010).

\section{Blood}

Blood was drawn from the cephalic vein using a 21 gauge $\times 3 / 4$ " Vacutainer blood collection set (Becton, Dickinson \& Co, Franklin Lakes, NJ) and sampled directly into $6 \mathrm{ml}$ Vacutainer Trace Element Tubes (one serum (with no additive) and one $\mathrm{K}_{2}$ EDTA tube (Becton, Dickinson \& Co, Franklin Lakes, JN)). Blood was sampled 2 weeks prior to starting the fish exposure, weekly from weeks 0-4 during the fish exposure, then every second week for weeks 6-12 of the exposure phase and the 10 week elimination phase (weeks 13-22). Hematocrit (Packed cell volume (PCV)) was determined during the acclimation phase and for weeks 2-22 of the study using the whole blood from the $\mathrm{K}_{2}$ EDTA tube drawn into a micro-hematocrit capillary tube (Fisher, Pittsburgh, PA) and centrifuged ( 3 minutes MCHT setting, 10,400 RPM, 12,600 g) using a Clay Adams Triac Centrifuge (Becton, Dickinson \& Co, Franklin Lakes, NJ). An additional 1-1.5 ml aliquot of whole blood was placed in a cryovial (Nalgene, Rochester, NY) for later $\mathrm{Hg}$ analysis, and the remaining whole blood was centrifuged ( 5 minutes blood separation setting, 3500 RPM, $1500 \mathrm{~g}$ ) using the Clay Adams Triac Centrifuge separated into plasma and packed cells (PCplasma). Blood from the serum tube was similarly centrifuged and separated into serum and packed cells (PCserum). Whole blood and the various blood compartments were kept frozen at $-20^{\circ} \mathrm{C}$ until analyzed.

\section{Hair}

Hair samples (a mixture of guard hairs and undercoat) were collected using an electronic hair clipper from each dog in the study three times: two weeks prior to being fed fish, the first day of week 0 and on the last day of the exposure (week 12). Hair samples were from over each animal's cephalic vein (foreleg hair). Hair was washed using a 1\% Triton-X 100 (EMD Serono, inc, Rockland MA, USA) soap solution, rinsed thoroughly and freeze dried using a Freezone 4.5 Freeze Dry System (Labconco, Kansas City, MO, USA).

\section{Mercury analysis}

$\mathrm{Hg}$ was determined using a DMA-80 direct $\mathrm{Hg}$ analyzer (Milestone, Sorisole, BG, Italy). Instruments were calibrated using a 6 point linear calibration curve from 0.25 $\mathrm{ng}$ to $7.00 \mathrm{ng}$. Samples were considered below detection limit (BDL) when the $\mathrm{Hg}$ detected in the sample was below $0.25 \mathrm{ng}$ for at least 2 of the repeated samples. Approximately 125-150 mg of blood or 10-20 mg of hair was analyzed at a time. All samples were analyzed in duplicate. A third sample was analyzed when results of the duplicates differed by more than $10 \%$ (blood) or when sample abundance permitted (hair). At the beginning of each run, blanks, aqueous standards of known Hg concentrations, and a certified reference material (DORM3 (National Research Council Canada, Ottawa ON, Canada) for runs with blood samples, IAEA-086 Human Hair (International Atomic Energy Agency Analytical Quality Control Services, Vienna, Austria) for runs with hair) were analyzed for quality assurance and control. Blanks were below $0.10 \mathrm{ng}, \mathrm{Hg}$, standards were all within $10 \%$ of expected values, and the total $\mathrm{Hg}$ concentration in the reference material was within the certified range.

\section{Calculations and Statistics}

For samples that were above detection limit $(>0.25 \mathrm{ng}$ of $\mathrm{Hg}$ ), differences among exposed dogs for blood matrices (whole blood, PCplasma, PCserum) were determined using a non-parametric Friedman test with all pairwise comparisons done using a Conover test [25]. $\mathrm{Hg}$ concentration in whole blood was adjusted for PCV and weight before comparisons. Time to $\mathrm{Hg}$ plateau for each matrix was determined using Scheffé multiple comparison identifying the earliest week not found to be significantly different from week 12 . Elimination was calculated assuming a two compartment open model with $1^{\text {st }}$ order elimination using the equation

$$
d \mathrm{Hg} / d \mathrm{t}=-\mathrm{k}_{\mathrm{e}} \mathrm{Hg}
$$

The $k_{\mathrm{e}}$ is the elimination rate constant expressed as week $^{-1}$ Half-life $\left(t_{1 / 2}\right)$ can be calculated as $t_{1 / 2}=0.693 / k_{e}$ [26]. Parameters (time to plateau, $k_{e}, t_{1 / 2}$ ) for individuals (dogs $\mathrm{C}, \mathrm{K}, \mathrm{M}$ and $\mathrm{T}$ ) were calculated separately as well as calculated using the combined results. Two models for 0 order (constant rate) elimination were also fit to the data for comparison of mean square error. Rate constants were calculated using the slope from week 12 (end of exposure) and week 22 (end of study) and a constant $1 \%$ loss due to red blood cell (RBC) turnover.

For each time period, differences between hair $\mathrm{Hg}$ for controls and fish-fed dogs were determined using a Kruskel-Wallis Test. Difference within each treatment (control or fish-fed) were evaluated using a Friedman test blocked by dog.

Calculations were performed using Microsoft Office Excel 2003 (Microsoft Corporation, USA) and statistical comparisons were done using StatsDirect version 2.7.8 (Altrincham, Cheshire, UK). An $\alpha<0.05$ was considered significant for all comparisons.

\section{Results}

\section{Exposure Estimation and Detection of Blood Mercury}

The $\mathrm{Hg}$ concentration mean $\pm \mathrm{SD}$ of the chum salmon was $45.5 \pm 11.8 \mathrm{ppb}$. Fish diet $\operatorname{dogs}(\operatorname{dogs} \mathrm{C}, \mathrm{K}, \mathrm{M}, \mathrm{T})$ were fed between 11.4 and $18.9 \mathrm{~g}$ fish $/ \mathrm{kg}$ BW per day (average 
Table 1 Amount fish fed.

\begin{tabular}{|c|c|c|c|c|c|c|c|c|}
\hline \multirow[b]{2}{*}{ week } & \multicolumn{2}{|c|}{$\operatorname{dog} C$} & \multicolumn{2}{|c|}{$\operatorname{dog} K$} & \multicolumn{2}{|c|}{$\operatorname{dog} M$} & \multicolumn{2}{|c|}{$\operatorname{dog} T$} \\
\hline & $\begin{array}{c}\mathrm{g} \text { fish } \\
\text { per meal } \\
\text { Mean } \pm S D\end{array}$ & $\begin{array}{c}\mathrm{g} \text { fish } \\
\text { per kg BW } \\
\text { Mean } \pm S D\end{array}$ & $\begin{array}{c}\mathrm{g} \text { fish } \\
\text { per meal } \\
\text { Mean } \pm S D\end{array}$ & $\begin{array}{c}\mathrm{g} \text { fish } \\
\text { per kg BW } \\
\text { Mean } \pm S D\end{array}$ & $\begin{array}{c}\mathrm{g} \text { fish } \\
\text { per meal } \\
\text { Mean } \pm S D\end{array}$ & $\begin{array}{c}\mathrm{g} \text { fish } \\
\text { per kg BW } \\
\text { Mean } \pm S D\end{array}$ & $\begin{array}{c}\mathrm{g} \text { fish } \\
\text { per meal } \\
\text { Mean } \pm S D\end{array}$ & $\begin{array}{c}\mathrm{g} \text { fish } \\
\text { per kg BW } \\
\text { Mean } \pm S D\end{array}$ \\
\hline 1 & $268 \pm 23.5$ & $15.0 \pm 1.31$ & $343 \pm 69.2$ & $16.4 \pm 3.31$ & $257 \pm 17.4$ & $12.0 \pm 0.82$ & $314 \pm 22.7$ & $13.8 \pm 1.00$ \\
\hline 2 & $267 \pm 11.8$ & $14.1 \pm 0.62$ & $322 \pm 30.1$ & $14.9 \pm 1.39$ & $255 \pm 10.9$ & $11.4 \pm 0.48$ & $295 \pm 46.3$ & $13.0 \pm 2.04$ \\
\hline 3 & $289 \pm 21.5$ & $15.3 \pm 1.14$ & $359 \pm 44.2$ & $16.3 \pm 2.01$ & $270 \pm 21.2$ & $12.0 \pm 0.94$ & $311 \pm 26.5$ & $14.1 \pm 1.20$ \\
\hline 4 & $266 \pm 31.4$ & $14.8 \pm 1.75$ & $362 \pm 44.1$ & $16.6 \pm 2.02$ & $256 \pm 17.4$ & $12.4 \pm 0.84$ & $306 \pm 45.5$ & $13.9 \pm 2.06$ \\
\hline 6 & $349 \pm 48.4$ & $18.9 \pm 2.63$ & $311 \pm 50.0$ & $14.2 \pm 2.29$ & $259 \pm 24.2$ & $13.0 \pm 1.21$ & $298 \pm 43.5$ & $13.5 \pm 1.97$ \\
\hline 8 & $322 \pm 36.8$ & $17.7 \pm 2.02$ & $294 \pm 29.5$ & $13.8 \pm 1.38$ & $241 \pm 22.0$ & $12.2 \pm 1.11$ & $273 \pm 41.0$ & $12.9 \pm 1.94$ \\
\hline 10 & $319 \pm 24.5$ & $18.5 \pm 1.42$ & $313 \pm 31.3$ & $15.0 \pm 1.50$ & $257 \pm 14.5$ & $13.3 \pm 0.75$ & $282 \pm 20.5$ & $13.6 \pm 0.99$ \\
\hline 12 & $312 \pm 38.9$ & $18.1 \pm 2.25$ & $338 \pm 43.9$ & $16.0 \pm 2.08$ & $261 \pm 13.9$ & $13.5 \pm 0.72$ & $304 \pm 38.3$ & $14.4 \pm 1.81$ \\
\hline
\end{tabular}

Average grams fish fed per meal and per kg dog weight during exposure. Variation in grams fish fed per kg body weight (BW) was due to the effort to maintain BW and condition by adjusting meal sizes as needed.

of $13.4 \pm 0.58 \mu \mathrm{g} \mathrm{Hg}$ per $\mathrm{kg}$ BW per day (Table 1), with variation to maintain $\mathrm{BW}$ and condition. The amount fed was used to estimate $\mathrm{Hg}$ exposure (Figure $1 \mathrm{~A}$ ). $\mathrm{Hg}$ was detectable in whole blood, PCplasma, and PCserum within 1 week after exposure (Figures 1B and 2) and plateaued within 3-8 weeks (average $=3-6$ weeks) (Table 2). During the exposure phase, $\mathrm{Hg}$ was detected just above the detection limit in plasma for $\operatorname{dog} \mathrm{K}$ at week 3 and in both plasma and serum for $\operatorname{dog} C$ in week 8 . All other plasma and serum sample time points were below detection limit.

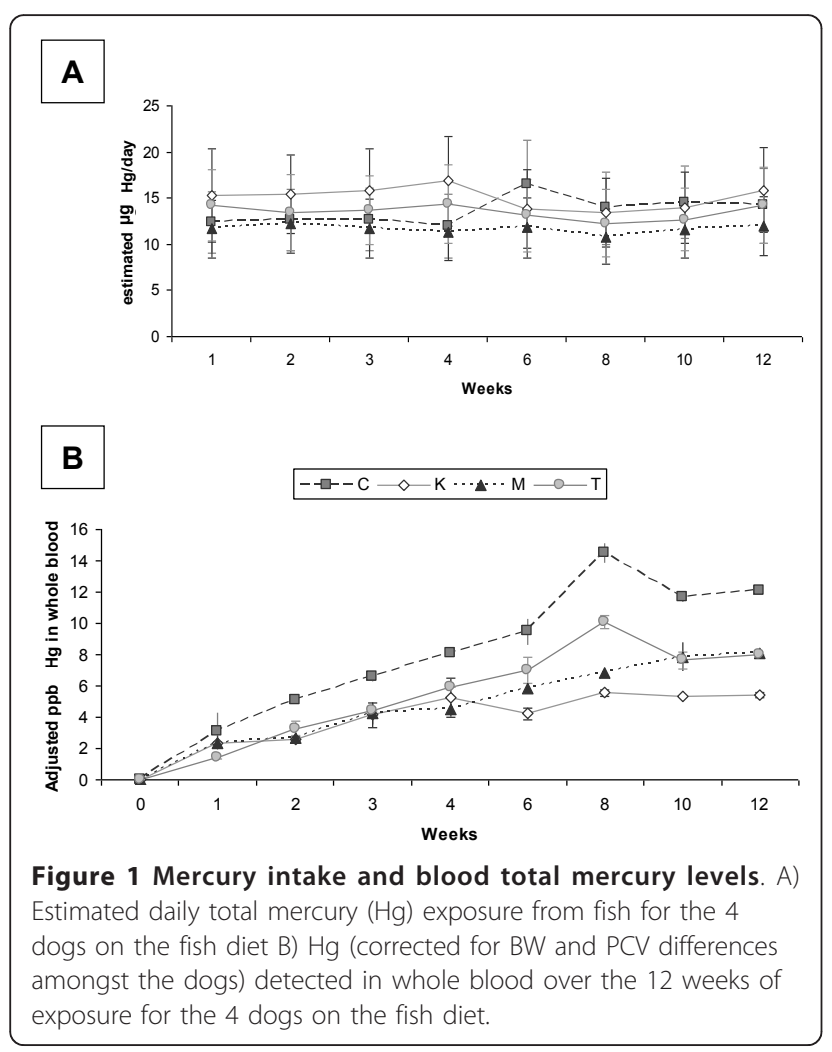

Hg was below detection limit for all matrices analyzed from the control dogs.

Within each exposed dog, $\mathrm{Hg}$ in PCserum and PCplasma did not vary significantly from each other. $\mathrm{Hg}$ in whole blood varied significantly from both PCserum and PCplasma $(P<0.0001$ for $\operatorname{dogs} C, \mathrm{M}, \mathrm{T}$ and $P=$ 0.0006 and $P=0.0002$ for PCserum and PCplasma, respectively, for $\operatorname{dog} \mathrm{K})$. For each blood compartment (whole blood, PCserum and PCplasma) all dogs varied significantly from each other ( $P$ ranged from 0.0339 to < $0.0001)$ with the exception of $\operatorname{dogs} \mathrm{M}$ and $\mathrm{T}$ for whole blood $(P>0.99)$ and PCserum $(P=0.35)$. For all dogs and all weeks, PCV ranged from 45.5 to $56.5 \%$. Within each dog across all weeks the average PCV was $51 \pm 3 \%$ ).

\section{Elimination}

All fish-fed dogs appeared to undergo first order elimination (Figure 3). The elimination half-life in whole blood for individual dogs ranged from 4.3 to 7.5 weeks (30 to 52.5 days), while the average for all fish-fed dogs was 7 weeks (49 days) (Table 2). Only dog K dropped below detection limit in all matrices before the end of the study. For all fish-fed dogs, the mean square error was lowest for the $1^{\text {st }}$ order elimination model. The mean square error for the $1^{\text {st }}$ order elimination model ranged from 215 times lower than the 0 -order model using the linear slope (average of $6 \pm 5$ times lower) and 2-7 times lower for the 0 -order model using the $1 \%$ RBC turnover model (average $3 \pm 2.1$ times lower).

\section{Mercury in hair}

There was no significant difference in hair $\mathrm{Hg}$ between control and fish-fed dogs for weeks -2 (acclimation) and week 0 . At week 12 (end of exposure) there was a significant $(P=0.02)$ increase in hair $\mathrm{Hg}$ between control and fish-fed dogs (Figure 4). Comparing results for each dog across all weeks evaluated, there was no significant 

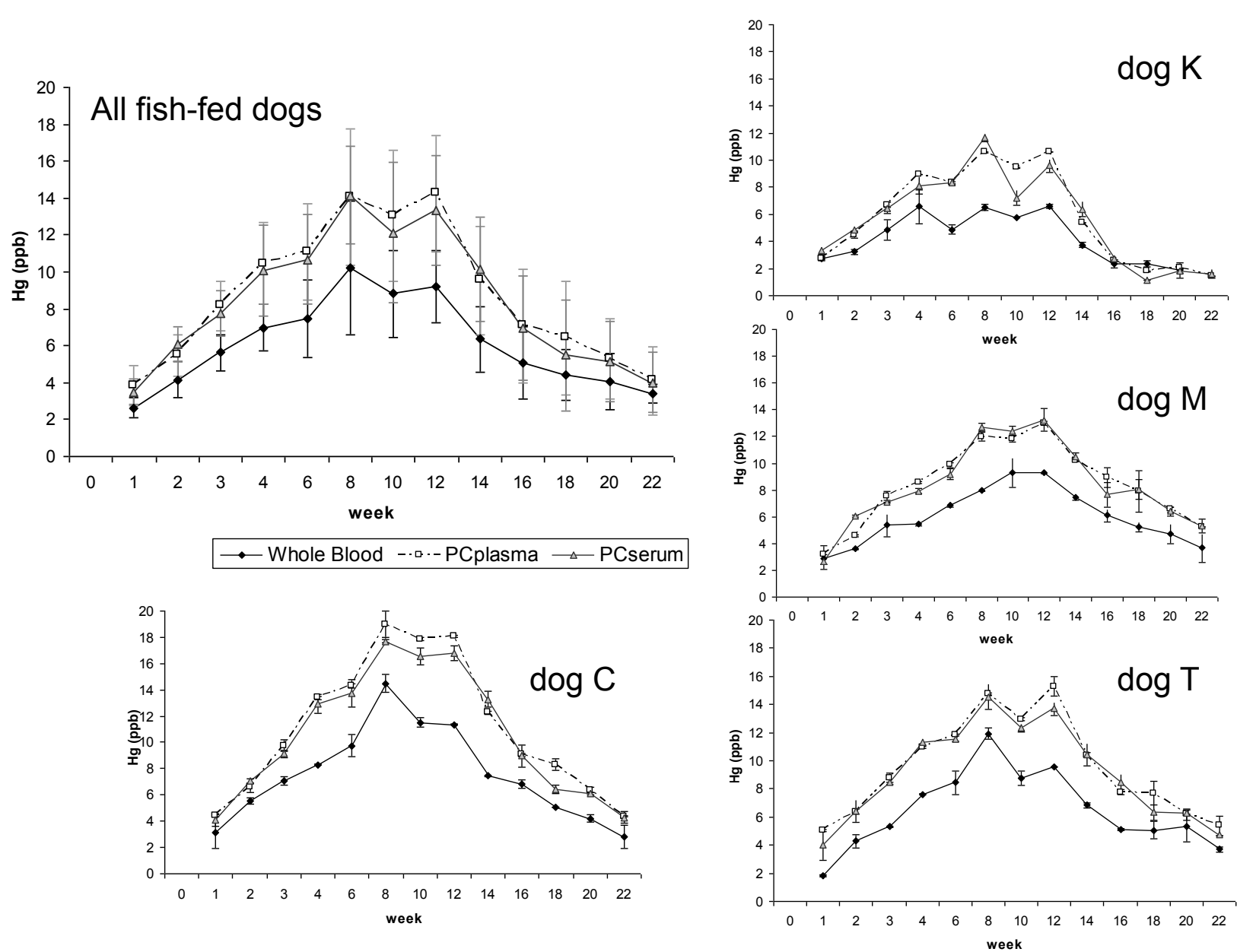

Figure 2 Mercury in blood compartments. Mercury $(\mathrm{Hg})$ detected in each blood compartment for each individual dog and all fish-fed dogs combined. Error bars represent differences in results amongst the repeated analysis for each sample.

difference in the control $\operatorname{dogs}(P=0.18)$, but there was a significant difference between the fish-fed dogs at week 12 compared to either week 0 or $-2(P=0.01)$. $\mathrm{Hg}$ in hair at week 12 was $6,13,5$, and 6 times greater than for weeks 0 and -2 for dogs $\mathrm{C}, \mathrm{K}, \mathrm{M}$, and $\mathrm{T}$ respectively. The ratio of $\mathrm{Hg}$ in hair to whole blood ranged from 54 to 69 (Table 2).

\section{Discussion}

We found that $\mathrm{Hg}$ from ingested fish increased to detectable concentrations in certain blood compartments within a week of exposure. Although there were differences in time to uptake and elimination amongst the chronically exposed dogs, in general, the patterns of uptake and elimination of $\mathrm{Hg}$ were similar. In addition, the rates of elimination determined for the dogs in this study were consistent with those predicted in toxicokinetic models for human exposure [24]. Because of this consistency, the sled dog model can be a powerful tool in better understanding the toxicology and toxicokinetics of $\mathrm{Hg}$ in piscivores, and warrants further detailed study, especially with respect to subarctic and arctic food webs.

$\mathrm{Hg}$ is compartmentalized primarily in the $\mathrm{RBCs}$ (packed cells), most likely binding to the sulfhydryl groups of hemoglobin and other proteins [27]. This is consistent with other studies that have assessed $\mathrm{Hg}$ in blood $[14,21,28]$. The lack of significance between PCserum and PCplasma within each individual dog supports the hypothesis that the $\mathrm{Hg}$ is carried primarily on or in the RBC fraction, and not detectably bound to other proteins in the serum or plasma at this level of $\mathrm{Hg}$ intake from fish. Future studies may consider analyzing only one or the other of the packed cell fractions, rather than both. Because the PCVs for the dogs in this study were relatively consistent, PCV did not significantly affect the comparisons. However, because of the primary compartmentalization of $\mathrm{Hg}$ in $\mathrm{RBCs}$ and the 
Table 2 Summary of toxicokinetic variables in various compartments (blood and hair)

\begin{tabular}{|c|c|c|c|c|c|c|}
\hline & Compartment & $\begin{array}{c}\mathrm{Hg} \text { at week } 12 \\
(\mathrm{ppb})\end{array}$ & Time to Plateau ${ }^{\text {a }}$ (weeks) & $\begin{array}{c}\mathbf{k}_{\mathrm{e}}^{\mathbf{b}} \\
\left(\text { weeks }^{-1}\right)\end{array}$ & $\begin{array}{c}t_{1 / 2} \\
\text { (weeks) }\end{array}$ & $\begin{array}{c}\text { Ratio } \mathrm{Hg} \\
\text { Hair:Blood }\end{array}$ \\
\hline \multirow[t]{4}{*}{$\operatorname{dog} C$} & WB: & 11.36 & 8 & -0.14 & -5.0 & 62 \\
\hline & PCp: & 18.98 & 8 & -0.14 & -4.9 & \\
\hline & PCs: & 16.80 & 6 & -0.14 & -5.1 & \\
\hline & Hair: & 704.9 & & & & \\
\hline \multirow[t]{4}{*}{$\operatorname{dog} K$} & WB: & 6.58 & 2 & -0.16 & -4.3 & 69 \\
\hline & PCp: & 10.64 & 4 & -0.21 & -3.3 & \\
\hline & PCs: & 9.60 & 3 & -0.21 & -3.4 & \\
\hline & Hair: & 456.6 & & & & \\
\hline \multirow[t]{4}{*}{$\operatorname{dog} M$} & WB: & 9.27 & 6 & -0.09 & -7.5 & 52 \\
\hline & PCp: & 12.99 & 8 & -0.09 & -7.7 & \\
\hline & PCs: & 13.24 & 8 & -0.09 & -7.6 & \\
\hline & Hair: & 488.1 & & & & \\
\hline \multirow[t]{6}{*}{$\operatorname{dog} T$} & WB: & 9.57 & 4 & -0.10 & -7.3 & 54 \\
\hline & PCp: & 15.28 & 6 & -0.11 & -6.6 & \\
\hline & WB: & 9.57 & 4 & -0.10 & -7.3 & 54 \\
\hline & PCp: & 15.28 & 6 & -0.11 & -6.6 & \\
\hline & PCs: & 13.71 & 4 & -0.11 & -6.6 & \\
\hline & Hair: & 526.0 & & & & \\
\hline Average $^{d}$ & WB: & $9.2 \pm 1.97$ & 3 & -0.10 & -7.0 & $59 \pm 7.6$ \\
\hline all fish- & PCp: & $14.2 \pm 3.18$ & 6 & -0.11 & -6.6 & \\
\hline \multirow[t]{2}{*}{ fed dogs } & PCs: & $13.3 \pm 2.95$ & 6 & -0.10 & -6.9 & \\
\hline & Hair: & $544 \pm 111.0$ & & & & \\
\hline
\end{tabular}

Total mercury $(\mathrm{Hg})$ concentration was determined at the end of fish exposure (week 12) for the fish-fed dogs and the rates to plateau and elimination for the different blood compartments (whole blood (WB), packed cells from plasma (PCp) and packed cells from serum (PCs)) were calculated.

${ }^{\mathrm{a}}$ Time to plateau was determined as the earliest time point found not to vary significantly from $\mathrm{Hg}$ concentration at week 12 ( $\alpha=0.05$ ).

${ }^{b} k_{e}$ is the first order elimination constant

${ }^{\mathrm{c}}$ Ratio $=\mathrm{Hg}$ Hair $(\mathrm{ppm}) / \mathrm{Hg}$ Whole Blood $(\mathrm{ppm})$

${ }^{\mathrm{d}}$ Analysis was done on the average of the combined parameter results

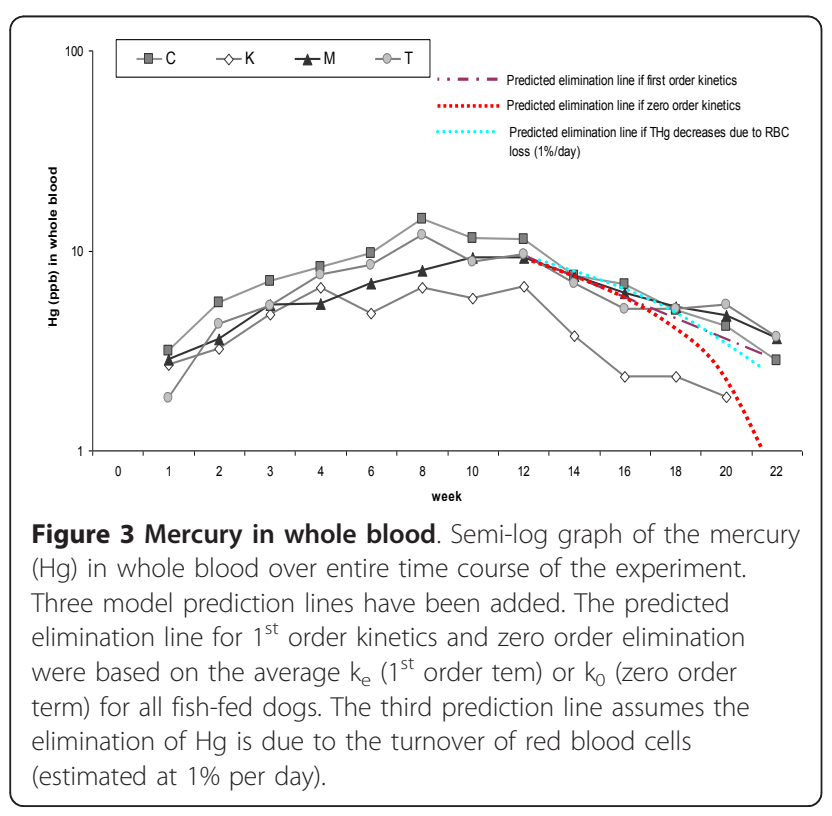

potential importance of $\mathrm{PCV}$ on $\mathrm{Hg}$ concentration in whole blood it is critical to also evaluate PCV. The sporadic detection of $\mathrm{Hg}$ in serum and plasma for dogs $\mathrm{K}$ and $\mathrm{C}$ may be related to the slightly greater amount of fish these dogs were fed. It is possible that with a diet higher in $\mathrm{Hg}$, an increased detection of $\mathrm{Hg}$ in plasma

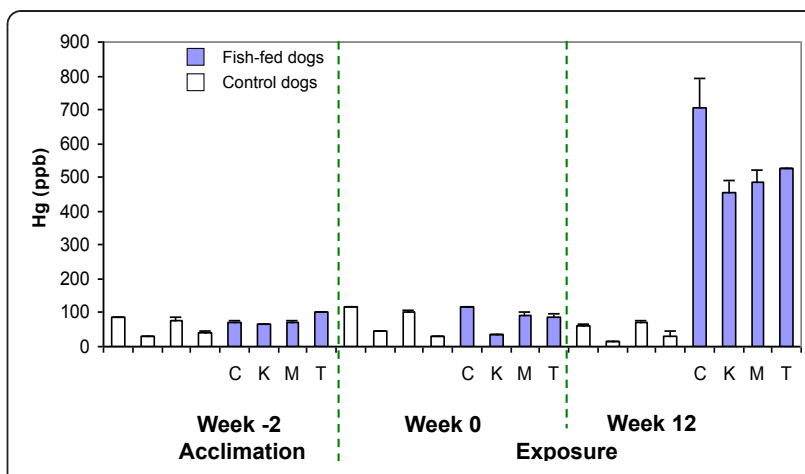

Figure 4 Mercury in hair. Comparison of mercury $(\mathrm{Hg})$ in hair between control and fish-fed dogs. Error bars represent the difference between repeated measures for each sample. 
and serum may occur. Based on other studies, this compartment (serum or plasma) would likely have a very different $k_{e}$ and $t_{1 / 2}$ compared to whole blood, PCplasma or PCserum assessed in this study [20,21]. This study represents exposure to a diet with a relatively low, but biologically and ecologically relevant, $\mathrm{Hg}$ concentration. Calculated rates may change with exposure to higher concentrations of $\mathrm{Hg}$, so this study should not be extrapolated as a model for exposure to high levels of dietary $\mathrm{Hg}$.

Based on this study, relatively low circulating concentrations of $\mathrm{Hg}$ appears to undergo $1^{\text {st }}$ order elimination. Prior research has determined that canine $\mathrm{RBC}$ turnover is around $1 \%$ per day (for a RBC lifespan of 100-115 days) [29]. If the primary route of elimination for $\mathrm{Hg}$ were through RBC turnover, we would expect the elimination curve to have more closely followed the zero-order elimination curves shown in Figure 3. The 1\% RBC turnover model does fit the data better than the average linear slope 0 -order model. This is likely due to the compartmentalization of $\mathrm{Hg}$ in RBCs and the contribution of RBC turnover to $\mathrm{Hg}$ elimination. Although the $1 \%$ RBC turnover model may provide an approximation of elimination rates when $\mathrm{k}_{\mathrm{e}}$ is unknown and $1^{\text {st }}$ order kinetics cannot be calculated, use of alternative models (such as the 1\% RBC turnover model) would result in underestimating predicted blood $\mathrm{Hg}$ concentrations at any given time, in addition to underestimating the time for elimination of $\mathrm{Hg}$ from blood.

Our canine model not only is of use in modeling canine $\mathrm{Hg}$ exposure, but it is also a good model for other piscivores including humans. The rate of elimination of $\mathrm{Hg}$ from blood determined in this study is more similar to that predicted by human models of toxicokinetics than the laboratory rodent models have found ( 49 days in this study, 52 days for humans [24], and 5.6-9.3 days in mice [20]). The estimated $\mathrm{Hg}$ intake level for the dogs in our study was $0.80 \mu \mathrm{g} / \mathrm{kg} \mathrm{BW} /$ day and was the equivalent of a $70 \mathrm{~kg}$ person eating $1 \mathrm{~kg}$ of fish a day. Although this is about twice the Alaska ADIL for humans, blood Hg in the dogs plateaued at 8-16 ppb which is below the $20 \mathrm{ppb}$ level Health Canada has applied as their limit for "normal" in their biomonitoring program [8].

The differences noted among the dogs, most notably $\operatorname{dog} \mathrm{K}$ (more rapid time to plateau, faster rate of elimination) may indicate genetic differences in $\mathrm{Hg}$ kinetics. In humans, differences in glutathione expression can significantly impact $\mathrm{Hg}$ elimination [30,31]. Whether the relationship between gene expression and $\mathrm{Hg}$ disposition is also true for canines has not been described. It is interesting that the dog $\mathrm{K}$ had the highest hair $\mathrm{Hg}$ to blood $\mathrm{Hg}$ ratio. It is possible that the more rapid elimination noted was due to sequestration in hair.

Hair proved to be a good indicator of exposure to $\mathrm{Hg}$ via a fish diet. In other mammals a linear relationship between hair and blood has been seen [32], and in humans it is used for risk assessments to predict blood $\mathrm{Hg}$ from hair concentrations [33]. In harbor seals the ratio of $\mathrm{Hg}$ in hair to $\mathrm{Hg}$ in blood is a bit lower (22 in females, 40 in males) [32] than was found in the sled dogs (average of about 59). In polar bears the ratio appears to be a bit higher than in the sled dogs (estimated at about $100 \times$ based on average blood and hair $\mathrm{Hg}$ ) [34]. However, for both these species the hair to blood ratio was much closer to the ratio found in this study than the ratio seen in humans ( $\mathrm{Hg}$ averages about 250× whole blood Hg concentration [33]). The differences may be due to the relative surface area and hair density in dogs, seals, polar bears and humans. Because $\mathrm{Hg}$ is primarily detected in RBCs, PCV may also be an important factor in differences seen.

The concentration of $\mathrm{Hg}$ detected in sled dog hair in this study (all below $1 \mathrm{ppm}$ ) was well below the concentration associated with toxicity in wildlife [35]. Subclinical neurological effects have been measured in polar bear brains at $\mathrm{Hg}$ concentrations associated with $6 \mathrm{ppm}$ in hair [35], and clinical neurological effects in mink at $\mathrm{Hg}$ concentrations over $30 \mathrm{ppm}$ in hair [36]. Although this study did not directly assess health effects on the sled dogs associated with exposure to $\mathrm{Hg}$ (such as renal damage, changes in thyroid hormones, and neurological damage [11,37-39]), it does demonstrate that sled dogs are an effective model for $\mathrm{Hg}$ exposure, and can be used to design future studies assessing health effects.

\section{Conclusions}

Overall, the sled dog model provides an effective surrogate for piscivorous species. Blood elimination rates are more similar to human rates than the more commonly used mouse or rat models. Additionally, hair $\mathrm{Hg}$ is an effective means of monitoring exposure to $\mathrm{Hg}$ via diet. Hair to blood ratios were found to be more similar to other mammalian species than humans, and could be useful in assessing risk to other species such as piscivorous wolves or marine mammals. This study evaluates $\mathrm{Hg}$ exposure in a manner that is reflective of populations (human or wildlife) relying on fish for subsistence as is still common in many areas of the circumpolar North.

\section{Abbreviations \\ Hg: Total mercury; ADIL: acceptable daily intake level; BW: body weight; RBC: red blood cell; PCplasma: packed RBCs from plasma; PCserum: packed RBCs from serum; WB: whole blood; $t 1 / 2$ : half-life; $k_{e}: 1^{\text {st }}$ order elimination constant.}

\section{Acknowledgements}

This project was supported by Alaska INBRE project "Mercury in the piscivore" (subproject of award number P20RR016466 from the National Center for Research Resources). The content is solely the responsibility of the authors and does not necessarily represent the views of the National Center 
for Research Resources or the National Institutes of Health. The authors would like to thank Shaina Bhojwani, Lucero Correa, Gabrielle Johnson, Sam Norlin, Rhonda Swor, Christine Terzi, and Rachel Witter for their help with blood collection and processing.

\section{Authors' contributions}

CLL participated in the study design and coordination, assisted with sample collection and $\mathrm{Hg}$ analysis, completed the statistical analysis and drafted the manuscript. SKM and JMC participated in sample collection and $\mathrm{Hg}$ analysis. JK prepared and analyzed the hair for $\mathrm{Hg}$ and preformed initial statistical analysis on the results. KH participated in the study design, fish exposure, and sample collection. TMO conceived of the study, participated in its design and coordination, in addition to sample collection. All authors read and approved the final manuscript.

\section{Competing interests}

The authors declare that they have no competing interests.

Received: 3 August 2011 Accepted: 7 December 2011

Published: 7 December 2011

\section{References}

1. Jewett SC, Duffy LK: Mercury in fishes of Alaska, with emphasis on subsistence species. Sci Total Environ 2007, 387:3-27.

2. Goldman LR, Shannon MW, the Committee on Environmental Health: Technical Report: Mercury in the environment: implications for pediatricians. Pediatrics 2001, 108:197-205.

3. Burger J, Gochfeld M: Mercury in canned tuna: white versus light and temporal variation. Environ Res 2004, 96:239-249.

4. Schoeman K, Bend JR, Hill J, Nash K, Koren G: Defining a lowest observable adverse effect hair concentrations of mercury for neurodevelopmental effects of prenatal methylmercury exposure through maternal fish consumption: a systematic review. Ther Drug Monit 2009, 31:670-682.

5. Myers GJ, Davidson PW: Prenatal methylmercury exposure and children: neurologic, developmental, and behavioral research. Environ Health Persp 1998, 106:841-847.

6. Huang L-S, Myers GJ, Davidson PW, Cox C, Xiao F, Thurston SW Cernichiari E, Shamlaye CF, Sloane-Reeves J, Georger L, Clarkson TW: Is susceptibility to prenatal methylmercury exposure from fish consumption non-homogeneous? Tree-structured analysis for the Seychelles Child Development Study. NeuroToxicology 2007, 28:1237-1244.

7. Verbrugge LA: Fish consumption advice for Alaskans: a risk management strategy to optimize the public's health. In State of Alaska Epidemiology Bulletin. Edited by: McLaughlin J, Gessner BD. Alaska Division of Public Health; 2007:

8. Health Canada: Human health risk assessment of mercury in fish and health benefits of fish consumption. Ottowa: Bureau of Chemical Safety Food Directorate Health Products and Food Branch; 2007.

9. Verreault J, Maisonneuve F, Dietz R, Sonne C, Letcher RJ: Comparative hepatic activity of xenobiotic-metabolizing enzymes and concentrations of organohalogens and their hydroxylated analogues in captive Greenland sledge dogs (Canis familiaris). Environ Toxicol Chem 2009, 28:162-172.

10. Sonne C, Leifsson PS, Dietz R, Kirkegaard M, Jensen AL, Shahmiri S, Letcher RJ: Greenland sledge dogs (Canis familiaris) develop liver lesions when exposed to a chronic and dietary low dose of an environmental organohalogen cocktail. Environ Res 2008, 106:72-80.

11. Sonne $C$ : Health effects from long-range transported contaminants in Arctic top predators: an integrated review based on studies of polar bears and relevant model species. Environ Int 2010, 36:461-491.

12. Letcher RJ, Bustnes JO, Dietz R, Jenssen BrM, Jørgensen EH, Sonne C, Verreault J, Vijayan MM, Gabrielsen GW: Exposure and effects assessment of persistent organohalogen contaminants in arctic wildlife and fish. Sci Total Environ 2010, 408:2995-3043.

13. Dunlap KL, Reynolds AJ, Bowers PM, Duffy LK: Hair analysis in sled dogs (Canis lupus familiaris) illustrates a linkage of mercury exposure along the Yukon River with human subsistence food systems. Sci Total Environ 2007, 385:80-85.

14. Woshner V, Knott KK, Wells R, Willetto C, Swor R, O'Hara TM: Mercury and selenium in blood and epidermis of bottlenose dolphins (Tursiops truncatus) from Sarasota Bay, FL: interaction and relevance to life history and hematologic parameters. EcoHealth 2008, 5:360-370.

15. Brookens TJ, O'Hara TM, Taylor RJ, Bratton GR, Harvey JT: Total mercury body burden in Pacific harbor seal, Phoca vitulina richardii, pups from central California. Mar Pollut Bul 2008, 56:27-41.

16. Al-Shahristani H, Al-Haddad IK: Mercury content of hair from normal and poisoned persons. J Radioanal Chem 1973, 15:59-70.

17. Ekino S, Susa M, Ninomiya T, Imamura K, Kitamura T: Minamata disease revisited: an update on the acute and chronic manifestations of methyl mercury poisoning. J Neurol Sci 2007, 262:131-144.

18. Farris FF, Dedrick RL, Allen PV, Smith JC: Physiological model for the pharmacokinetics of methyl mercury in the growing rat. Toxicol Appl Pharm 1993, 119:74-90.

19. Carrier G, Brunet RC, Caza M, Bouchard M: A toxicokinetic model for predicting the tissue distribution and elimination of organic and inorganic mercury following exposure to methyl mercury in animals and humans. I. Development and validation of the model using experimental data in rats. Toxicol Appl Pharm 2001, 171:38-49.

20. Sundberg J, Jönsson S, Karlsson MO, Hallén IP, Oskarsson A: Kinetics of methylmercury and inorganic mercury in lactating and nonlactating mice. Toxicol Appl Pharm 1998, 151:319-329.

21. Schultz IR, Newman MC: Methyl mercury toxicokinetics in channel catfish (Ictalurus punctatus) and largemouth bass (Micropterus salmoides) after intravascular administration. Environ Toxicol Chem 1997, 16:990-996.

22. Fournier F, Karasov WH, Kenow KP, Meyer MW, Hines RK: The oral bioavailability and toxicokinetics of methylmercury in common loon (Gavia immer) chicks. Comp Biochem Phys A 2002, 133:703-714.

23. Rice DC: Blood mercury concentrations following methyl mercury exposure in adult and infant monkeys. Environ Res 1989, 49:115-126.

24. Carrier G, Bouchard M, Brunet RC, Caza M: A toxicokinetic model for predicting the tissue distribution and elimination of organic and inorganic mercury following exposure to methyl mercury in animals and humans. II. Application and validation of the model in humans. Toxicol Appl Pharm 2001, 171:50-60.

25. Conover WJ: Practical Nonparametric Statistics. 3 edition. Wiley; 1999.

26. Shargel L, Yu ABC: Applied Biopharmaceutics and Pharmacokinetics. 4 edition. Stamford: Appleton \& Lange; 1999.

27. Hughes WL: A physiochemical rationale for the biological activity of mercury and its compounds. Ann NY Acad Sci 1957, 65:454-460.

28. Weed R, Eber J, Rothstein A: Interaction of mercury with human erythrocytes. J Gen Physiol 1962, 45:395-409.

29. Carter MW, Matrone G, Mendenhall W: Estimation of the life span of red blood cells. J Gen Physiol 1964, 47:851-858.

30. Gundacker C, Komarnicki G, Jagiello P, Gencikova A, Dahmen N, Wittmann K, Gencik M: Glutathione-S-transferase polymorphism, metallothionein expression, and mercury levels among students in Austria. Sci Total Environ 2007, 385:37-47.

31. Custodio HM, Broberg K, Wennberg M, Jansson J-H, Vessby B, Hallmans G, Stegmayr B, Skerfving S: Polymorphisms in glutathione-related genes affect methylmercury retention. Arch Environ Health 2004, 59:588-595.

32. Brookens TJ, Harvey JT, O'Hara TM: Trace element concentrations in the Pacific harbor seal (Phoca vitulina richardii) in central and northern California. Sci Total Environ 2007, 372:676-692.

33. Budtz-Jørgensen E, Grandjean P, Jørgensen PJ, Weihe P, Keiding N: Association between mercury concentrations in blood and hair in methylmercury-exposed subjects at different ages. Environ Res 2004, 95:385-393.

34. Cardona-Marek T, Knott KK, Meyer BE, O'Hara TM: Mercury concentrations in Southern Beaufort Sea polar bears: variation based on stable isotopes of carbon and nitrogen. Environ Toxicol Chem 2009, 28:1416-1424.

35. Dietz R, Born EW, Riget F, Aubail A, Sonne C, Drimmie R, Basu N: Temporal trends and future predictions of mercury concentrations in northwest Greenland polar bear (Ursus maritimus) hair. Environ SciTechnol 2011, 45:1458-1465.

36. Basu N, Scheuhammer AM, Bursian SJ, Elliott J, Rouvinen-Watt K, Chan HM: Mink as a sentinel species in environmental health. Environ Res 2007, 103:130-144.

37. Sonne C, Dietz R, Leifsson PS, Asmund G, Born EW, Kirkegaard M: Are liver and renal lesions in East Greenland polar bears (Ursus maritimus) associated with high mercury levels? Environ Health-Glob 2007, 6:1-14. 
38. Basu N, Scheuhammer AM, Sonne C, Letcher RJ, Born EW, Dietz R: Is dietary mercury of neurotoxicological concern to wild polar bears (Ursus maritimus)? Environ Toxicol and Chem 2009, 28:133-140.

39. Pilsner RJ, Lazarus AL, Nam D-H, Letcher RJ, Sonne C, Dietz R, Basu N: Mercury-associated DNA hypomethylation in polar bear brains via the LUminometric methylation assay: a sensitive method to study epigenetics in wildlife. Mol Ecol 2010, 19:307-314.

doi:10.1186/1751-0147-53-66

Cite this article as: Lieske et al.: Toxicokinetics of mercury in blood compartments and hair of fish-fed sled dogs. Acta Veterinaria Scandinavica 2011 53:66.

Submit your next manuscript to BioMed Central and take full advantage of:

- Convenient online submission

- Thorough peer review

- No space constraints or color figure charges

- Immediate publication on acceptance

- Inclusion in PubMed, CAS, Scopus and Google Scholar

- Research which is freely available for redistribution

Submit your manuscript at www.biomedcentral.com/submit
() Biomed Central 